\title{
Etika Kedokteran dalam Kerjasama Periklanan dengan Sponsor
}

\author{
Rianto Setiabudy ${ }^{1,2}$, Broto Wasisto ${ }^{1}$, Bachtiar Husein ${ }^{1}$ \\ ${ }^{\mathrm{I}}$ Majelis Kehormatan Etik Kedokteran Pengurus Besar Ikatan Dokter Indonesia \\ ${ }^{2}$ Departemen Farmakologi, Fakultas Kedokteran Universitas Indonesia, Jakarta
}

\author{
Kata Kunci \\ Etika, dokter, iklan, sponsor \\ Korespondensi \\ contact@ilmiah.id \\ Publikasi \\ (C) $2020 \mathrm{JEKI} /$ ilmiah.id \\ DOI \\ I0.26880/jeki.v4iI.45
}

Tanggal masuk: 3I Desember 2019

Tanggal ditelaah: 12 Januari 2020

Tanggal diterima: to Februari 2020

Tanggal publikasi: 24 Februari 2020

\begin{abstract}
Abstrak Kerjasama antara dokter atau perhimpunan profesi dengan industri dalam upaya pengiklanan produk tertentu berpeluang cukup besar untuk menyebabkan dokter atau perhimpunan profesi masuk ke dalam konflik kepentingan. Dalam kondisi demikian, para profesional medis ini harus berupaya maksimal untuk memberikan pesan edukasi kepada masyarakat, mempertahankan independensi, dan menjaga integritas profesi. Dalam kerjasama ini, dokter atau perhimpunan profesi tidak dibenarkan dalam bentuk apa pun ikut atau memberi kesan ikut mempromosikan suatu produk tertentu. Dokter atau perhimpunan profesi dibenarkan membuat iklan edukasi. Sponsor boleh menyatakan dukungannya terhadap pesan edukasi itu dalam tayangan terpisah dengan jedah waktu yang cukup sedemikian sehingga orang tahu bahwa itu pesan yang datang dari sponsor. Dokter dan perhimpunan profesi seyogyanya juga tidak boleh ikut tampil dalam promosi produk yang disamarkan sebagai diskusi kesehatan di televisi atau radio
\end{abstract}

\begin{abstract}
Partnership between doctors or medical associations with industries to promote the marketing of particular products undoubtedly places the medical profession in a conflict of interest. Under this unfavorable condition, the medical profession must do their best to provide educational message for the society, maintain independency as well as their professional integrity. In this collaboration doctors and the medical association in whatever way are not allowed to participate in the promotion of any particular product(s). Doctors and the medical associations are allowed to construct educational advertisement. The sponsor may show their support to the message in the educational advertisement in a separate time or place in a such way that that people understand that it comes from the sponsor. Doctors and the medical associations are not allowed to participate in any product promotional program which are disguised as health discussion programs in the television or radio.
\end{abstract}

Iklan dalam bentuk tayangan di televisi, radio, media cetak, dan sebagainya adalah sarana yang sering digunakan oleh produsen obat, alat kesehatan, suplemen makanan, minuman, dan lain-lain untuk memperkenalkan produknya ke pada konsumen. Dalam upaya memenangkan persaingan dagang, kerap kali produsen membutuhkan pernyataan dukungan dari profesi medis. Ini bersandar pada kenyataan bahwa hingga saat ini pernyataan dokter mendapat kepercayaan yang tinggi dari masyarakat. Apa yang dikatakan dokter dianggap mengandung nilai kebenaran yang tidak perlu diragukan lagi.

Sementara itu, dokter maupun perhimpunan profesi membutuhkan biaya baik untuk kepentingan pribadi maupun untuk menjalankan kegiatan organisasi. Karena itu, kerjasama dokter dengan produsen atau sponsor menjadi sesuatu yang amat menarik. Honor yang diberikan oleh sponsor bisa mencapai ratusan juta rupiah. Sebagai seorang profesional, dokter atau perhimpunan profesi harus mengatakan hal yang benar, berimbang, dan bertujuan mencerdaskan masyarakat. Namun, sebagai pihak yang menerima honor dari sponsor, ada dorongan kuat baginya untuk memuji suatu produk secara berlebihan, menyampaikan pesan yang tidak berimbang, atau menakutnakuti masyarakat yang semuanya bertujuan membantu sponsor meningkatkan penjualan produknya. Dengan demikian amat jelas bahwa 
dokter maupun perhimpunan profesi dokter yang bekerjasama dengan sponsor masuk ke dalam konflik kepentingan.

Kondisi konflik kepentingan ini harus dijauhi karena, walaupun belum tentu bersalah, dokter atau perhimpunan profesi yang bersangkutan sudah amat dekat dengan pelanggaran etika dan hukum. Majelis Kehormatan Etika Kedokteran Ikatan Dokter Indonesia (MKEK IDI) sebenarnya sangat menginginkan agar dokter dan perhimpunan profesi tidak terlibat dalam kerjasama periklanan dengan sponsor, namun desakan dari mereka demikian kuatnya sehingga MKEK memberikan toleransi yang disertai ramburambu etika agar tidak terjadi dampak negatif yang dapat mencederai marwah profesi dokter. Dalam kepustakaan tidak sulit bagi kita untuk mencari informasi mengenai rambu etika bagi dokter terkait masalah mengiklankan dirinya sendiri, tapi tidak ada yang membahas mengenai kerjasama dengan industri yang mengiklankan produknya.

\section{Manifestasi Kerja Sama}

Keterlibatan dokter dalam iklan promosi produk bisa muncul dalam beberapa bentuk:

1. Partisipasi dalam iklan edukasi (terkadang disebuttulisan atau artikel edukasi) di televisi, radio, atau media cetak. Di sini, dokter atau perhimpunan profesi menyampaikan pesan sederhana agar masyarakat bisa hidup sehat, padahal tujuan utamanya ialah menunjang penjualan produk tertentu. Misalnya, masyarakat dianjurkan untuk minum cukup, menggunakan sabun pada waktu mandi, membersihkan gigi setelah makan, menjaga kesehatan jantung, dan lainlain. Tujuan sebenarnya ialah menunjang penjualan produk tertentu air mineral, sabun mandi, odol, suplemen penurun kadar kolesterol, dan sebagainya.

2. Partisipasi dalam tayangan televisi atau siaran iklan berbentuk diskusi mengenai masalah kesehatan. Dokter yang dilibatkan terkadang menggunakan jas dokter, namun ada juga yang tidak menggunakan jas dokter, tapi berulang kali disapa dengan panggilan "dokter". Terkadang ada juga yang menyebut dirinya sebagai "praktisi kesehatan”.

Dalam diskusi ini, dokter sering hanya mengulas segi medisnya, sedangkan pesanpesan untuk membeli produk disampaikan oleh petugas marketing dari sponsor. Namun, terkadang juga terjadi hal yang lebih buruk lagi yaitu dokter secara gamblang ikut menganjurkan orang membeli produk yang dipromosikan itu.

3. Partisipasi dokter dalam siaran iklan di radio biasanya muncul dalam bentuk obrolan mengenai masalah kesehatan tertentu namun bila disimak terlihat jelas bahwa tujuan sebenarnya dari obrolan itu membujuk masyarakat membeli produk tertentu. Diskusi seperti ini jelas adalah kegiatan promosi produk yang disamarkan sebagai diskusi kesehatan.

Ada satu lagi bentuk tayangan di televisi atau siaran radio yang sering melibatkan dokter, yaitu yang bersifat murni layanan kesehatan masyarakat. Tayangan/siaran/ artikel demikian sama sekali tidak berkaitan dengan tujuan promosi produk tertentu, dan tujuannya semata-mata untuk meningkatkan kesadaran masyarakat mengenai kesehatan. Sponsornya bisa Kementerian Kesehatan atau organisasi kesehatan tertentu yang tidak berafiliasi dengan industri. Tayangan atau siaran demikian ini sangat terpuji dari sudut pandang etika kedokteran.

\section{Pedoman terkait Etika Kedokteran dalam Periklanan}

1. Kode Etik Kedokteran Indonesia pasal 3:

"Dalam melakukan pekerjaan kedokterannya, seorang dokter tidak boleh dipengaruhi oleh sesuatu yang menyebabkan hilangnya kebebasan dan kemandirian profesi."

2. Sumpah Dokter butir 2:

"Saya akan menjalankan tugas dengan cara yang terhormat dan bersusila sesuai dengan martabat pekerjaan saya sebagai dokter."

3. Sumpah Dokter butir 3:

"Saya akan memelihara dengan sekuat tenaga, martabat dan tradisi luhur profesi kedokteran." 


\section{Kajian dari Segi Etika Kedokteran}

1. Artikel/tulisan/iklan edukasi harus dibuat dengan tujuan utama mendidik masyarakat untuk hidup sehat. Bahwasanya ada kepentingan promosi produk tertentu, yang secara de facto terkait di sini, adalah tujuan tambahan.

2. Semua orang bisa memahami bahwa promosi adalah upaya yang wajar bila dilakukan oleh pabrik pembuat produk tertentu, namun tidak pada tempatnya bila seorang dokter atau perhimpunan profesi ikut berpromosi untuk menjual produk tersebut

3. Pengertian artikel/tulisan/iklan edukasi harus dibedakan dengan iklan biasa. Iklan edukasi menyandang nama "edukasi" maka isi artikel/tulisan/iklan edukasi harus berimbang, objektif, bersifat mendidik, tidak berbohong, menakut-nakuti atau melanggar norma kepantasan/ kesusilaan yang berlaku bagi masyarakat Indonesia. Materi untuk tulisan edukasi seyogyanya dibuat oleh dokter atau perhimpunan.

Iklan biasa dibuat oleh orang-orang yang bekerja untuk produsen dan sifatnya lain sekali dari iklan edukasi karena ia boleh menonjolkan berbagai kelebihan suatu produk tanpa mengungkapkan kelemahannya. Iklan biasa tidak membawa misi edukasi karena tujuannya ialah meningkatkan penjualan produk. Sampai batas tertentu, iklan biasa masih diperbolehkan "menimbulkan sedikit rasa takut" agar produknya dibeli orang, misalnya menyatakan betapa berbahayanya rumah yang tidak dilengkapi dengan alat pemadam api. Yang tidak diperbolehkan di sini hanyalah menjelekkan produk pesaingnya. Semuanya ini ada dalam ranah etika bisnis, bukan etika kedokteran.

4. Artikel/tulisan/iklan edukasi harus disusun oleh orang-orang yang kompeten, dalam hal ini dokter atau perhimpunan profesi. Para dokter atau perhimpunan profesi yang membuat iklan edukasi semacam ini jelas terancam oleh konflik kepentingan karena mendapat imbalan finansial dari produsen. Karena itu, mereka harus berupaya maksimal untuk tetap objektif dan menjaga marwah profesi kedokteran.

5. Sponsor tidak boleh ikut campur dalam penyusunan artikel/tulisan/iklan edukasi, namun ia boleh menampilkan dukungannya atau pesan promosinya pada tempat atau waktu yang berdekatan tulisan/iklan edukasi itu sedemikian rupa sehingga orang tahu bahwa itu adalah pesan sponsor. Untuk tayangan di televisi, pesan sponsor dibawakan bukan oleh dokter penyampai pesan edukasi dan diberi jarak waktu minimal 3 detik. Untuk siaran radio, suara pembawa pesan sponsor tidak boleh menggunakan suara dokter pembawa pesan edukasi. Untuk tulisan edukasi diberi bingkai yang berbeda.

6. Draft artikel/tulisan/iklan edukasi itu perlu dikonsultasikan dan disetujui oleh MKEK IDI sebelum ditayangkan di televisi, disiarkan melalui radio, atau disebarluaskan melalui media cetak.

7. Tulisan yang tampilannya menyerupai tulisan/artikel/iklan edukasi, namun substansinya adalah semata untuk tujuan promosi harus ditulis dengan jelas kata "IKLAN" di sudut kiri atau kanan atasnya. Tulisan sedemikian ini disusun oleh pabrik pembuat produk. Dokter dan perhimpunan profesi tidak diperkenankan membuatnya.

8. Iklan biasa di media cetak maupun televisi (yang dibuat oleh produsen), tidak boleh menampilkan penyampai pesan yang menggunakan seragam dokter, atau memberi kesan bahwa ia adalah dokter, atau menampilkan lambang IDI, atau menggunakan nama/lambang perhimpunan profesi, atau nama yang dilengkapi dengan gelar dokter, atau ia dipanggil dengan sebutan "Dokter". Hal ini tidak berlaku untuk tayangan yang sifatnya murni untuk layanan/edukasi masyarakat.

9. Iklan biasa di radio/TV juga tidak boleh menimbulkan kesan bahwa penyampai pesan adalah seorang dokter, baik atas nama pribadi atau mewakili perhimpunan profesi.

10. Harus dihindarkan semua tindakan/ tayangan/pernyataan apa pun yang dapat menimbulkan kesan perhimpunan profesi atau dokter secara pribadi ikut berpromosi, 
misalnya: menempelkan logo perhimpunan pada produk, menyatakan bahwa perhimpunan profesi merekomendasikan produk tertentu, memuji-muji produk tertentu, membuat testimoni, dan sebagainya.

\section{KESIMPULAN}

Perkembangan jaman mengakibatkan timbulkan kebutuhan kerja sama antara dokter/ perhimpunan profesi dengan produsen dalam periklanan untuk menunjang promosi produk tertentu. Kerjasama ini memberi manfaat finansial bagi bagi dokter/perhimpunan profesi, namun juga sekaligus menempatkan mereka dalam konflik kepentingan. Dalam kondisi demikian, para profesional medis ini harus berupaya maksimal untuk memberikan pesan edukasi yang objektif kepada masyarakat, mempertahankan independensi, dan menjaga integritas profesi. Adanya rambu atau pegangan etika akan sangat membantu profesi dokter untuk menjaga agar mereka tidak sampai mencederai marwah etika profesi dan tetap menjunjung tinggi etika kedokteran. Selain itu, adanya pegangan etika ini juga membantu produsen untuk memahami sudut pandang dari etika kedokteran.

\section{KONFLIK KEPENTINGAN}

Penulis tidak memiliki konflik kepentingan dalam penulisan artikel ini.

\section{REFERENSI}

1. Pengurus Besar Ikatan Dokter Indonesia. Kode Etik Kedokteran Indonesia 2012

2. Sumpah Dokter Indonesia

3. The AMA Position Statement on Advertising and Public Endorsement. athttps://ama. com.au/position-statement/advertisingand-public-endorsement-2004-editoriallyrevised-2006-revised-2014

4. Anonim. Guide to professional conduct and ethics for registered medical practitioners 